through the intercellular spaces at a rate independent of stomatal aperture.

Such a wide range of topics, which must eventually be co-ordinated in an understanding of photosynthesis, may confuse the non-specialist, particularly as the arrangement is not such as to emphasize their interrelationship. The reader will miss the informal discussions which add greatly to any meeting; and I regret that in this series, and in this volume in particular, no general editor is appointed to consider the contents of each volume as a whole and to supply an introductory survey for the guidance of the non-specialist.

C. P. Whittingham

\section{SELECTIONS FROM PARACELSUS}

\section{Paracelsus}

Selected Writings. Edited with an Introduction by Jolande Jacobi. Translated by Norbert Guterman. Pp. 347. (London: Routledge and Kegan Paul, Ltd., 1951.) 25s, net.

T

HIS book is a sort of Paracelsian anthology, although not the first by any means, as the literature on Paracelsus is already voluminous. Many attempts have been made to translate and clarify the works of the man who was "one of the most enigmatical figures in history", and surely one of the strangest. According to Dr. J. Jacobi, Paracelsus has a greater message for us than he had for our fathers, although more than four hundred years have elapsed since his death. "Like him, we are living in a time of great transition: we, too, are bridges across an impetuous stream, connecting a sinking shore with a shore that is barely beginning to emerge." Even to-day the ideas of Paracelsus may suggest to modern minds the way to a new reality.

But the task of interpretation is hard. The German of Paracelsus is not easy to translate, his meaning is often confused and ambiguous, and he is anything but a polished writer. Nevertheless, he reflects those values which are, and always will be, indispensable to the Christian civilization.

His basic motif is man, as the beginning and centre of all creation. Few writers before him, and scarcely anyone after him, have conceived an anthropocentric system so lofty and at the same time so rational. It is a question, however, whether the present selections from the works of Paracelsus do not err on the side of over-simplification. The author confesses to having omitted "specifically medical material", "the paraphernalia of superstition", and "all polemical and eccentric texts" ; accordingly, the Paracelsian scholar may well wonder what is left. Nevertheless, as an introduction to a deeper study, the book will serve as a useful guide to that mass of confused learning which Paracelsus produced, and which is still so baffling to scholars.

The story of his wandering life and of his constant struggle for recognition is told in the introductory chapter. Then follow many selections from the works of "this strange Renaissance personality, so amply endowed with genius" - to quote from the foreword of Prof. Jung.

Of course, Paracelsus retained much of the medieval outlook : his idea that the human body consisted of mercury, sulphur and salt shows how he clung to the humoral conception, a view which, in various forms, persisted until almost the eighteenth century.
As for his philosophy, it is a quaint combination of ancient and modern thought. The reader must choose for himself those passages which are for him the most suggestive and stimulating. Of course, he will not agree with all the views expressed; but at least they may evoke constructive thinking - a great achievement for any writer.

Each of the passages may be traced to its source with the aid of a key at the end of the book. There are also a glossary to expound the obscure terms, and a bibliography of Paracelsian literature. The woodcuts, not all very clearly reproduced, are 148 in number: the source of each is listed, and they serve to re-create the medieval atmosphere. Unfortunately, the book lacks an index. Nevertheless, it is a reliable introduction to Paracelsus. Each reader must decide for himself whether to join the diminishing ranks of those who view Paracelsus as the 'prince of charlatans', or the rising tide of those who acclaim him as the 'king of physicians and philosophers': there is no middle course.

Dougras Guthrie

\section{DESIGN AND THEORY OF OXIDE-COATED CATHODES}

\section{The Oxide-Coated Cathode}

By Dr. G. Herrmann and Dr. S. Wagener. Translated by Dr. S. Wagener. Vol. 1: Manufacture. Pp. viii +148 ; 21s. net. Vol. 2: Physics, including Thermal Emission from Metals and Semi-Conductors. Pp. xiv $+311 ; 42 s$. net. (London: Chapman and Hall, Ltd., 1951.)

HIS translation of Drs. G. Herrmann and S. Wagener's well-known "Die Oxydkathode" is the first comprehensive work on the subject to appear in English since 1934, when Riemann's classic "Thermionic Emission" was published. It is all the more welcome because the earlier book was based on a physical model which is now outmodednamely, the view that the high specific emission from oxide cathodes is due to a surface monolayer of metallic barium. During the period 1934-39, experimental work, guided by the theoretical concepts of semi-conductor behaviour proposed by A. H. Wilson, led most investigators to the view that the oxide layer behaves as an excess semi-conductor and that surface effects play only a subordinate part in the emission. During the Second World War, although great experimental progress was made, particularly in the field of pulsed emission, theoretical work was neglected. Since the War many physicists have become interested in semi-conductors, and many studies have been devoted both to the technical and to the laboratory behaviour of oxide cathodes. The situation to-day is, broadly, that there are two schools of thought: that which affirms the general truth of the semi-conductor theory; and a second which believes the cathode to behave as a semiconductor at temperatures well below the operating range, but considers that conduction through an electron gas in the pores of the crystalline mass is a dominant feature in the operating range. The clearest experimental evidence for the first school is in work carried out by Hannay, Macnair and White, while the researches of Loosjes and Vink provide support for the second view. Various compromises between the schools have also been suggested. 